\title{
Sensory features of thiacalix[4]arene molecules towards volatile halogen-aromatic compounds
}

\author{
Z.I. Kazantseva ${ }^{1}$, I.A. Koshets ${ }^{1 *}$, O.M. Zaharenko ${ }^{1}$, S.G. Kharchenko ${ }^{2}$, V.I. Kalchenko ${ }^{2}$ \\ ${ }^{I}$ V. Lashkaryov Institute of Semiconductor Physics, NAS of Ukraine, \\ 41, prospect Nauky, 03680 Kyiv, Ukraine \\ ${ }^{2}$ Institute of Organic Chemistry, NAS of Ukraine, \\ 5, Murmanska str., 02660 Kyiv, Ukraine \\ *E-mail: koshets@isp.kiev.ua
}

\begin{abstract}
This work reports on the investigation of sensory properties of thiacalix[4]arene molecules towards volatile halogen-aromatic compounds. Experiments were carried out using the 8-channel sensory system based on Quartz Crystal Microbalance (QCM) technique. Kinetic responses, concentration dependences and detection limit have been obtained. It has been shown that interaction of the sensitive layer with the analyte molecules is substantially defined by the chemical structure of thiacalix[4]arene. Thus, thiacalix[4]arene materials considered in this paper are of great interest for application in the sensory systems of "Electronic Nose" type.
\end{abstract}

Keywords: QCM sensor, thiacalix[4]arene, halogen-aromatic compounds.

https://doi.org/10.15407/spqeo23.01.41

PACS 07.07.Df

Manuscript received 30.09.19; revised version received 20.12.19; accepted for publication 18.03.19; published online 23.03.19.

\section{Introduction}

Similarly to freons, halogen derivatives of carbon aromatic compounds are actively involved in the photochemical reactions occurring in atmosphere. As a result, atmosphere is polluted with both halogen derivatives and products of their transformation and interaction with other air pollutants $[1,2]$. The analysis of these compositions of harmful chemicals is quite complicated. Thus, under sunlight radiation bromobenzene, bromide propyl and other bromine and fluorine compounds (in the presence of pollutants of nitrogen oxides, sulfur, etc.) are converted to cyclic and other compounds that are significantly more toxic than the original ones. For example, chlorobenzene is very toxic for aquatic flora and fauna with the long-term aftermath. Not only cyclic but all halogenated carboncarbons are more toxic to humans and animals than the corresponding hydrocarbons. Halogen derivatives of aromatic compounds possess light narcotic properties, irritate the respiratory tract, and harm the liver. The most potentially dangerous is fluorobenzene, volatility of which is much higher as compared to other mono-substituted halogen derivatives. The maximum permissible concentration (MPC) of fluorobenzene is at the level of several $\mathrm{mg} / \mathrm{m}^{3}$, while for chlorobenzene - tens of $\mathrm{mg} / \mathrm{m}^{3}[3,4]$. So, the possibility to create sensors sensitive to these toxic substances is a very important task.

Calixarenes (CA) are macrocyclic compounds that due to their bowl-like structure are of great interest in supramolecular chemistry for the purpose of constructing new molecules with outstanding complexing properties based on them $[5,6]$. Calixarenes are capable to form Host-Guest complexes in the gas phase, in solutions, in the crystalline state and in two-dimensional phases - thin films [7]. Chemosensors based on calixarene thin films have been used to create devices capable of recognizing cations, anions and neutral organic molecules in solutions (artificial tongue) or in the air (artificial nose) [8-13].

\section{Experimental}

This paper is devoted to studying the several thiacalix[4]arene molecules that are potentially capable to form Host-Guest complexes with halogen-aromatic volatile compounds. Taking into account the previous experiments [14], sensitive materials C904, C906, C907, C908, C912, C913, C917, C920 (nomenclature accepted at the Institute of Organic Chemistry, NAS of Ukraine, where these compounds were synthesized) have been 
<smiles>CCCCN1C(=O)c2ccccc2C1=O</smiles>

C912<smiles>CCCCP(=O)(CCCC)CCCCOc1c(SC(C)(C)C)cc(C(C)(C)C)cc1C(C)C</smiles>

C907<smiles>CCCCP(=O)(CCCC)Oc1c(OC)cccc1Sc1cc(Br)cc(C(C)(C)C)c1O</smiles>

C904<smiles>CCP(=O)(CC)CCCCOc1c(SC(C)(C)C)cc(C(C)(C)C)cc1C(C)(C)C</smiles>

C908<smiles>CSc1cc(C(C)(C)C)cc(C)c1OCC(=S)N(C)C</smiles>

C917<smiles>CSc1cc(C(C)(C)C)cc(C(C)(C)C)c1OCCCC[P+](O)(O)c1ccccc1</smiles>

C913<smiles>CCCOc1c(SC)cc(C(C)(C)C)cc1Sc1cc(C(C)(C)C)cc(C)c1O</smiles>

C906<smiles>CCOC(=O)COc1ccc(C(C)(C)C)cc1Sc1cc(C(C)(C)C)ccc1OCC(=O)OCC</smiles>

C920

Fig. 1. Chemical formulas of thiacalix[4]arenes.

Table. Detection limits (in ppm) of the sensor array with respect to analytes under study.

\begin{tabular}{|c|c|c|c|c|c|c|c|c|}
\hline $\begin{array}{c}\text { Sensitive } \\
\text { layer } \\
\text { analyte }\end{array}$ & $\mathbf{C 9 1 2}$ & $\mathbf{C 9 0 4}$ & $\mathbf{C 9 1 7}$ & $\mathbf{C 9 0 6}$ & $\mathbf{C 9 0 7}$ & $\mathbf{C 9 0 8}$ & $\mathbf{C 9 1 3}$ & $\mathbf{C 9 2 0}$ \\
\hline fluorobenzene & 15 & 25 & 20 & 20 & $<10$ & $<10$ & 25 & 500 \\
\hline chlorobenzene & 20 & 25 & 20 & 20 & $<10$ & 10 & 15 & 250 \\
\hline bromobenzene & 25 & 100 & 50 & 50 & 10 & 15 & 15 & 700 \\
\hline
\end{tabular}

chosen for our study. Their structural formulas are presented in Fig. 1. All of them (except C904) are the thiacalix[4]arenes functionalized with tert-butyl groups on the upper rim and different (phosphorylated, bromine and nitrogen containing, etc.) functional groups on the lower rim. Several halogen-aromatic compounds, namely: fluorobenzene $\left(\mathrm{C}_{6} \mathrm{H}_{5} \mathrm{~F}\right)$, chlorobenzene $\left(\mathrm{C}_{6} \mathrm{H}_{5} \mathrm{Cl}\right)$ and bromobenzene $\left(\mathrm{C}_{6} \mathrm{H}_{5} \mathrm{Br}\right)$, were used as analytes.

\subsection{Experimental set-up}

Quartz Crystal Microbalance (QCM) sensors are widely used in many practical applications in gaseous and liquid media as mass-sensitive sensors, for material characterization, etc. The QCM measurement technique uses the sensitivity of quartz crystal resonator with respect to any mass change at its surface in according to Sauerbrey relation [15]. Sensitivity of QCM technique is quite high - mass change of nanogram (and less) scale can be easily observed. When being used as a chemical sensor, the quartz surface covered with special coating is called the sensitive layer.

QCM-based chemosensory device designed and fabricated at the V. Lashkaryov Institute of Semiconductor Physics, NAS of Ukraine, was used [16]. The device consists of 8-channel QCM-based sensor array, operation cell, gas-supplying pathways, vapour injection system, air filter-drier providing fresh dry air for purification sensors between sampling, valve for switching "sampling" - "purification" and electronics (quartz oscillators, frequency counters, and interfacing with PC). Experiment controlling and data acquisition were carried out by means of original software. Standard radio-technical quartz elements $(10 \mathrm{MHz}, \mathrm{AT}$-cut, $\varnothing 8 \mathrm{~mm}$ ) covered with appropriable thiacalix[4]arene sensitive layers were used as the sensor elements. 


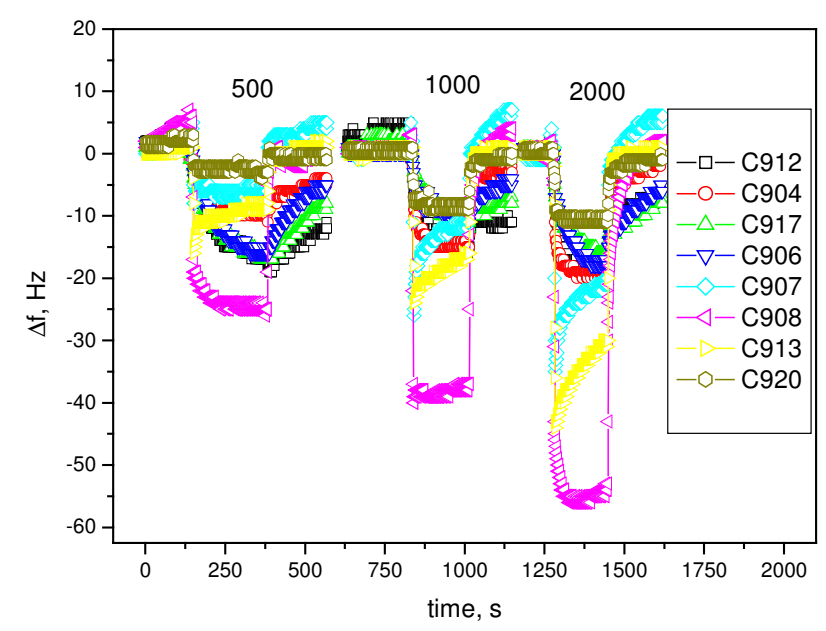

a)

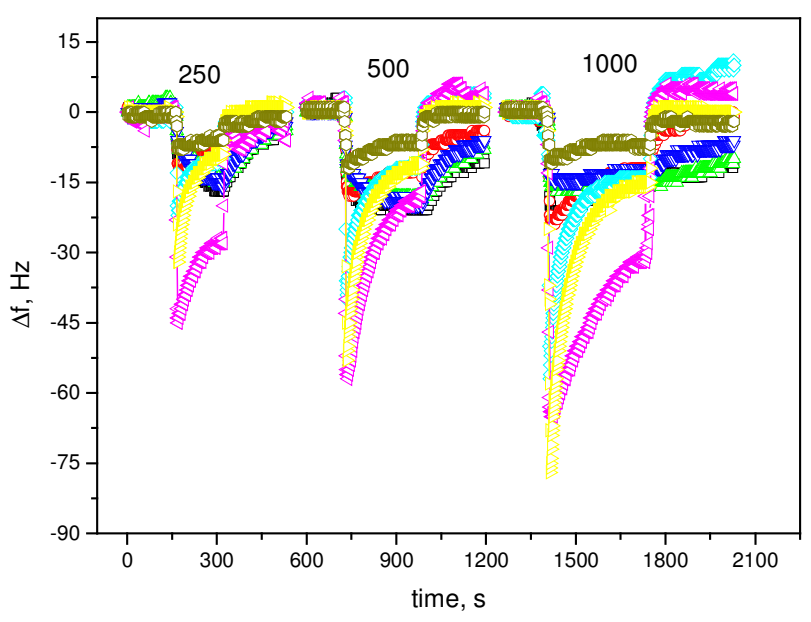

b)

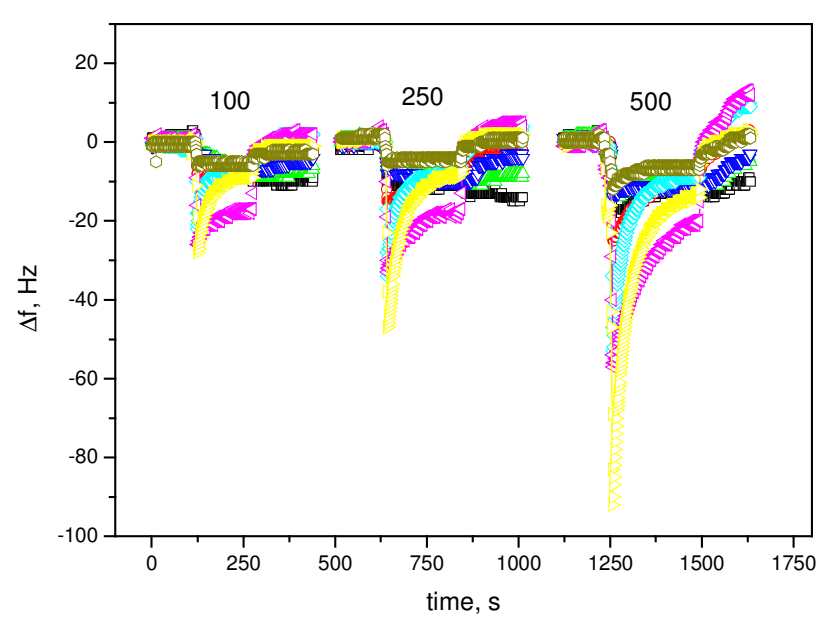

c)

Fig. 2. Kinetic responses of sensor arrays on consequent injection of fluorobenzene (a), chlorobenzene (b) and bromobenzene (c) into operation cell. The numerical values in the plots correspond to the analyte concentration in $\mathrm{ppm}$.

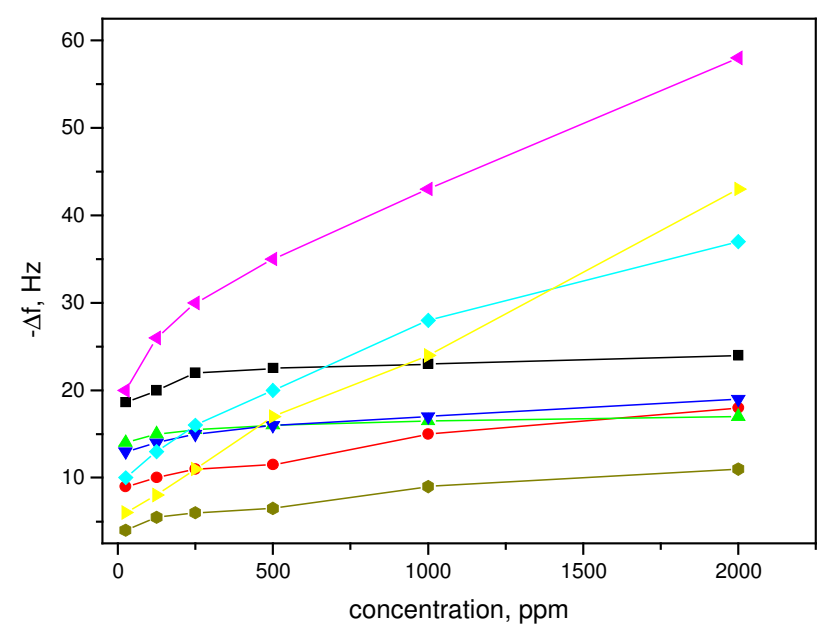

a)

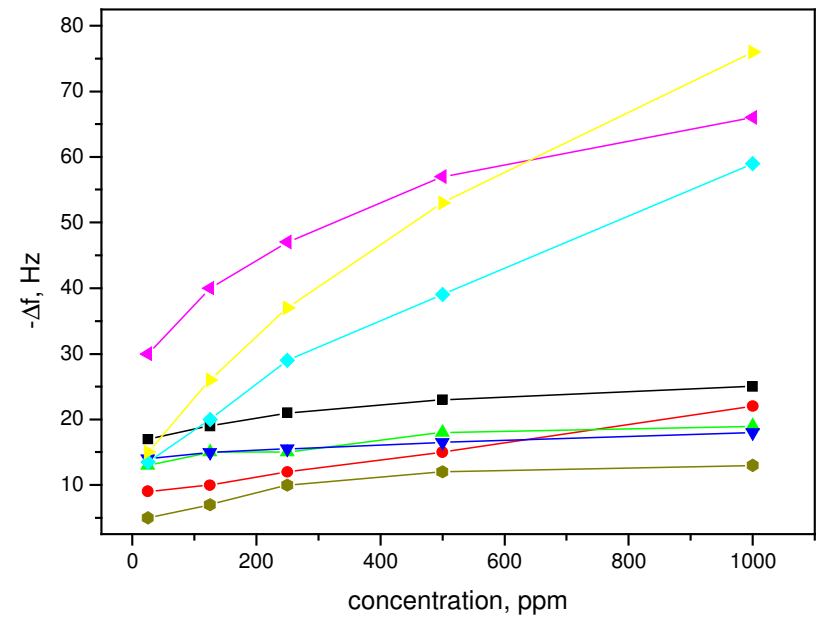

b)

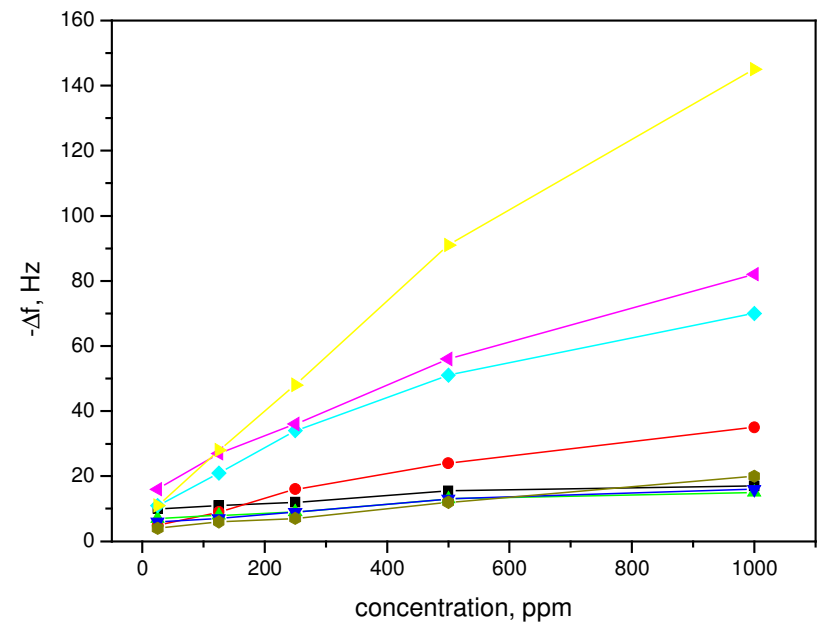

c)

Fig. 3. Concentration dependences of sensor arrays to fluorobenzene (a), chlorobenzene (b) and bromobenzene (c). 


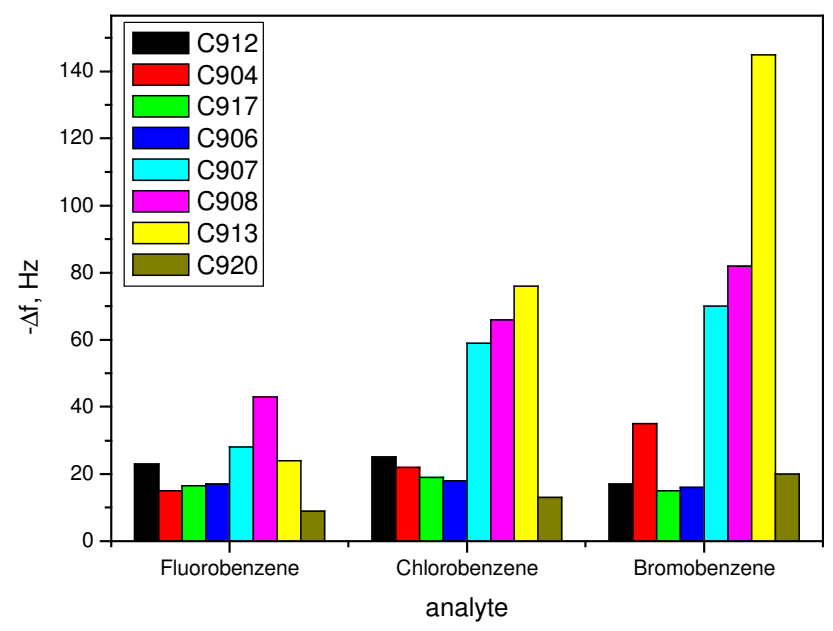

Fig. 4. Histogram of sensor array responses on $1000 \mathrm{ppm}$ of each analytes under study.

\subsection{Sensitive layers and the deposition method}

For immobilization of the thiacalix[4]arene sensing layers well-proven, the centrifugation (spin-coating) and the spreading drop methods have been used. For sensory applications, it is necessary to choose sensitive materials that are able both to efficiently bind guest-molecules and quickly release them during the purification stage of experiment. Therefore preliminary testing of the thiacix[4]arene sensitive layers was carried out using a simplified (single-channel) QCM sensor system. Quality and uniformity of the films obtained were observed with AFM and ellipsometry. The QCM baseline frequency shift due to layer loading on the quartz surface ("effective" film thickness) was within the range $5000 \ldots 6000 \mathrm{~Hz}$.

\section{Results and discussions}

Typical kinetic dependences of sensor array responses to the sequential injection of fluorobenzene (a), chlorobenzene (b) and bromobenzene (c) into operation cell are shown in Fig. 2. The numerical values above the curves correspond to the analyte concentration in ppm. The legend is given only in the first plot.

As seen from the kinetic responses of the sensory system, interaction of the sensitive layer with the analyte molecules is substantially defined by the chemical structure of CA. Kinetic responses for different analytes are significantly altered.

The concentration dependences of the sensor array towards corresponding analytes are presented in Fig. 3.

They are quite linear. Calixarenes C907 and C908 show rather high sensitivity towards analytes under study. C913 is turned out to be the most sensitive towards halogen-aromatic compounds, while its sensitivity to benzene is negligible [17]. C920 is linear oligomer, not a cyclic one, possesses good sensitivity to benzene but poorly sensitive to halogen-aromatic compounds. There are phosphoryl functional groups in the lower rim of all these three materials.
The structures of these materials contain phosphoryl functional groups in the lower rim, which distinguishes them from all other studied CAs, except for C904, which differs from the others in the structure of the upper rim. This difference in the adsorption features of C904 and C907 indicates the important role both of functional groups and vase-like structure in the specific adsorption processes.

Measurements of detection limits of the sensor arrays were carried out as well. The respective results are summarized in Table.

For better visual perception of the overall picture regarding to the selectivity, the responses of the sensor arrays on $1000 \mathrm{ppm}$ of each analyte are represented by the histogram in Fig. 4. The responses to 1000-ppm concentration clearly represent rather good selectivity of thiacalix[4]arenes involved in our experiments. It should be noted that C913 showed very high sensitivity to halogen-aromatic compounds, especially to bromobenzene even higher than just due to molecular weight increasing.

\section{Conclusion}

As stated above, the kinetic response under adsorption and desorption processes is a significantly informative parameter, account of which highly increases discriminative ability of sensor array under analyte identification. Since the magnitude of signal for the same analyte concentrations is different, the kinetics of responses are altered for different gases. Due to this fact, thiacalix[4]arene materials considered above are of great interest for application in the sensory systems of "Electronic Nose" type.

It has been shown that the sensory elements with thiacalix[4]arene C907, C908, C913 films are sensitive towards halogen-aromatic compounds at the WEEL (Workplace Environmental Exposure Level) level and lower.

Rather large difference in adsorption capability of the studied thiacalix[4]arene molecules towards aromatic and halogen-aromatic compounds can be explained in terms of Host-Guest complexation with applying the methods of molecular modeling based on quantumchemical calculations.

\section{References}

1. Pradyot Patnaik. A Comprehensive Guide to the Hazardous Properties of Chemical Substances. John Wiley \& Sons, 2007.

2. Nicholson W.J., and Moore J.A. Health Effects of Halogenated Aromatic Hydrocarbons. Ann. N. Y. Acad. Sci. 1979.

3. https://www.cdc.gov/niosh/ershdb/index_un.html

4. https://www.cdc.gov/niosh/npg/npgd0121.html

5. Gutsche C.D. Calixarenes: An Introduction (Monographs in Supramolecular Chemistry). $2^{\text {nd }}$ ed. Royal Society of Chemistry, Cambridge, 2008.

6. Vicens J., Harrowfield J. (Eds.) Calixarenes in the Nanoworld. Dodrecht, Springer, 2007. 
7. MacGillivray L.R., Atwood J.L. Unique guest inclusion within multi-component, extended-cavity resorcin[4]arenas. Chem. Communs. 1999. No 2. P. 181-182.

https://doi.org/10.1039/A808835G.

8. Koshets I.A., Kazantseva Z.I., Shirshov Yu.M., Cherenok S.A., Kalchenko V.I. Calixarene films as sensitive coatings for QCM-based gas sensors. Sensors and Actuators. B. 2005. 106. P. 177-181. https://doi.org/10.1016/j.snb.2004.05.054.

9. Koshets I.A., Kazantseva Z.I., Belyaev A.E., Kalchenko V.I. Sensitivity of resorcinarene films towards aliphatic alcohols. Sensors and Actuators. B. 2009. 140. P. 104-108.

https://doi.org/10.1016/j.snb.2009.04.014

10. Montmeat P., Veignal F., Methivier C., Pradier C.M., Hairault L. Study of calixarenes thin films as chemical sensors for the detection of explosives. Appl. Surf. Sci. 2014. 292. P. 137-141. https://doi.org/10.1016/j.apsusc.2013.11.101.

11. Temel F., Tabakci M. Calix[4]arene coated QCM sensors for detection of VOC emissions: methylene chloride sensing studies. Talanta. 2016. 153. P. 221-227.

https://doi.org/10.1016/j.talanta.2016.03.026.

12. Temel F., Ozcelik E., Ture A.G., Tabakci M. Sensing abilities of functionalized calix[4]arene coated QCM sensors towards volatile organic compounds in aqueous media. Appl. Surf. Sci. 2017. 412. P. $238-251$ https://doi.org/10.1016/j.apsusc.2017.03.258.

13. Pinalli R., Pedrini A. and Dalcanale E. Biochemical sensing with macrocyclic receptors. Chem. Soc. Rev. 2018. 47. P. 7006-7026. https://doi.org/10.1039/C8CS00271A.

14. Kharchenko S.G., Kazantseva Z.I., Koshets I.A., Kozlova T.V., Shishkina S.V., Ryabitskii A.B., Kalchenko V.I. Phosphorylthiacalixarenes as sensors for volatile organic molecules. Functional Materials. 2017. 24, No. 4. P. 1-8.

15. Sauerbrey G. Verwendung von Schwingquartzen zur Wagung dunner Schichten und zur Mikrowagung. Z. Physik. 1959. 155. P. 206-222.

16. Kalchenko V.I., Koshets I.A., Matsas E.P., Kopylov O.N., Solovyov A., Kazantseva Z.I., Shirshov Yu.M. Calixarene based QCM sensors array and its response to volatile organic vapors. Mater. Sci. 2002. 20, No 3. P.73-88.

17. Unpublished results - report on fulfilment of the scientific Project "Chemosensory system of "Electronic Nose" type for biomedical and ecological application" in the frame of Complex R\&D Program "Sensory systems for medicalecological and industrial-technological demands". Kyiv-2017.

\section{Authors and CV}

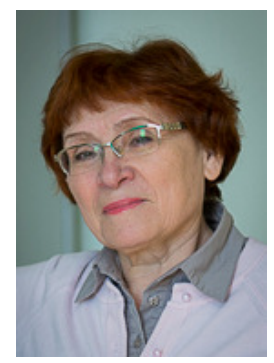

Z.I. Kazantseva is Ph.D. in Physics and Mathematics, Senior Researcher at the V. Lashkaryov Institute of Semiconductor Physics, NAS of Ukraine. The area of scientific interests of Z.I. Kazantseva includes thin organized films, LB-technology and sensory materials.

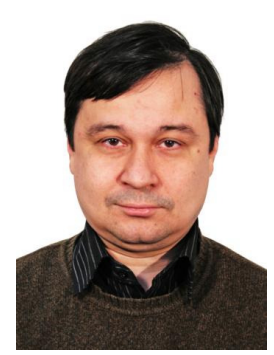

I.A. Koshets is Ph.D. in Physics and Mathematics, Senior Researcher at the V. Lashkaryov Institute of Semiconductor Physics, NASU. The area of scientific interests of I.A. Koshets includes development of bio- and chemical sensors, software and electronics for sensory applications.

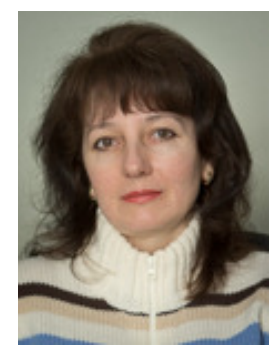

O.M. Zaharenko is Junior Researcher at the V. Lashkaryov Institute of Semiconductor Physics, NAS of Ukraine. The area of scientific interests of O.M. Zaharenko includes preparations of chemical sensors and carrying out experiments on QCM-based chemosensory systems.

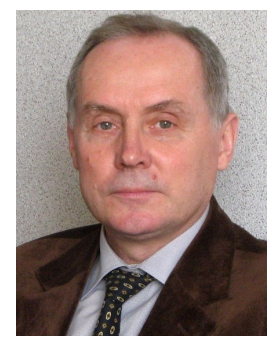

V.I. Kalchenko is Academician of NAS of Ukraine, Professor, Doctor of Science in Organic Chemistry, Head of the Institute of Organic Chemistry, NASU. The area of scientific interests of Prof. V.I. Kalchenko includes calixarenes, organophosphorus chemistry, supramolecular chemistry, design and synthesis of novel materials.

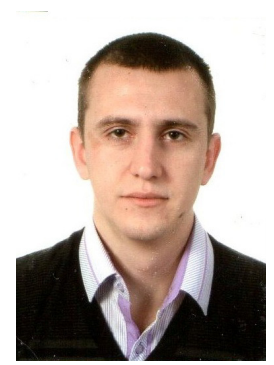

S.G. Kharchenko is Ph.D. in Chemistry, Researcher at the Institute of Organic Chemistry, NAS of Ukraine. His scientific interests are chemistry of thiacalixarenes, supramolecular chemistry, organophosphorus chemistry. 